Case Report

\title{
Mutation in LEMD3 (Man1) Associated with Osteopoikilosis and Late-Onset Generalized Morphea: A New Buschke-Ollendorf Syndrome Variant
}

\author{
Benjamin Korman, ${ }^{1}$ Jun Wei, ${ }^{1}$ Anne Laumann, ${ }^{2}$ Polly Ferguson, ${ }^{3}$ and John Varga ${ }^{1}$ \\ ${ }^{1}$ Division of Rheumatology, Northwestern University Feinberg School of Medicine, Chicago, IL, USA \\ ${ }^{2}$ Department of Dermatology, Northwestern University Feinberg School of Medicine, Chicago, IL, USA \\ ${ }^{3}$ Department of Pediatrics, University of Iowa Carver College of Medicine, Iowa City, IA, USA \\ Correspondence should be addressed to Benjamin Korman; benjamin-korman@northwestern.edu
}

Received 18 January 2016; Accepted 26 April 2016

Academic Editor: Jeung-Hoon Lee

Copyright (C) 2016 Benjamin Korman et al. This is an open access article distributed under the Creative Commons Attribution License, which permits unrestricted use, distribution, and reproduction in any medium, provided the original work is properly cited.

Introduction. Buschke-Ollendorf syndrome (BOS) is an uncommon syndrome characterized by osteopoikilosis and other bone abnormalities, accompanied by skin lesions, most frequently connective tissue nevi. BOS is caused by mutations in the LEMD3 gene, which encodes the inner nuclear membrane protein Manl. We describe a unique case of osteopoikilosis associated with lateonset localized scleroderma and familial LEMD3 mutations. Case Report. A 72-year-old woman presented with adult-onset diffuse morphea and bullous skin lesions. Evaluation revealed multiple hyperostotic lesions (osteopoikilosis) suggestive of BOS. DNA sequencing identified a previously undescribed nonsense mutation (Trp621X) in the LEMD3 gene encoding Man1. Two additional family members were found to have osteopoikilosis and carry the same LEMD3 mutation. Conclusions and Relevance. We report a unique familial LEMD3 mutation in an individual with osteopoikilosis and late-onset morphea. We propose that this constellation represents a novel syndromic variant of BOS.

\section{Introduction}

Osteopoikilosis is a rare autosomal dominant skeletal dysplasia characterized by multiple hyperostotic lesions. The bone lesions are generally symmetric but distributed irregularly and are typically detected as incidental radiographic findings [1]. Osteopoikilosis can be an isolated skeletal abnormality or may occur in association with diverse cutaneous manifestations as a component of Buschke-Ollendorf syndrome (BOS) (OMIM166700) $[2,3]$. The cutaneous manifestations of BOS, commonly manifesting in childhood, include connective tissue nevi and less frequently elastomas, collagenomas, and dermatofibrosis lenticularis (also called hypertrophic scar disseminata) [4-6]. The genetic basis for BOS was identified in 2004 by genome-wide linkage studies. These studies uncovered a mutation in LEMD3 (LEM domain containing 3) gene [2]. The LEMD3 gene encodes the $60 \mathrm{kD}$ inner nuclear membrane protein Man1. Mutations in LEMD3 are also linked to skeletal abnormalities other than BOS. These include isolated (nonsyndromic) osteopoikilosis [2] and melorheostosis, a hyperostotic anomaly characterized by radiolucent "dripping wax" appearance in the cortex of long bones $[7,8]$. Of note, melorheostosis itself may be an isolated radiological finding or occur in association with abnormalities in adjacent soft tissue, including linear scleroderma [912].

Morphea is a localized form of scleroderma characterized by skin induration in localized areas. Morphea has the highest incidence in childhood and young adults. Lateonset morphea is considerably less common. In contrast to systemic sclerosis, morphea is confined to the skin and is not associated with extracutaneous manifestations. The spectrum of morphea disorders includes linear scleroderma, plaque morphea, and diffuse morphea, which in rare cases may be extensive (pansclerotic morphea). Morphea lesions commonly occur on the extremities and the face and less 


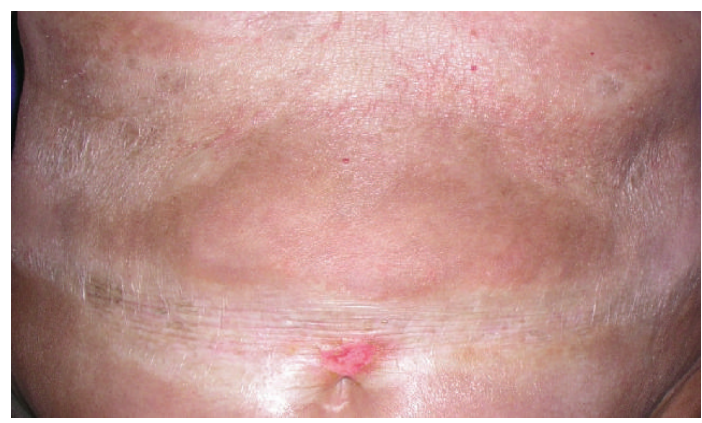

(a)

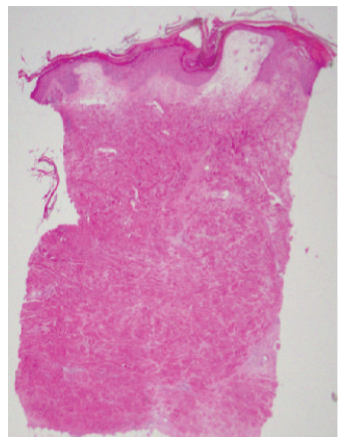

(d)

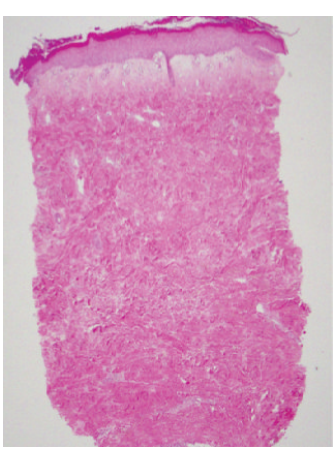

(e)

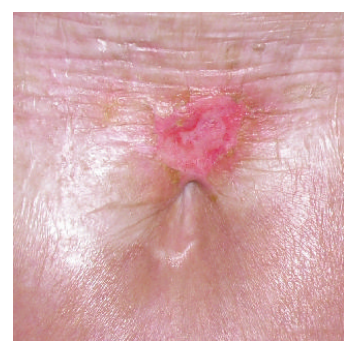

(b)

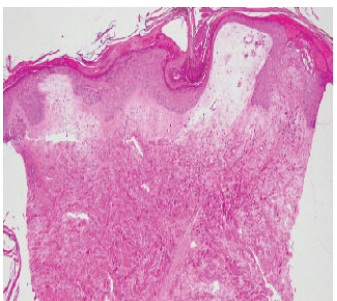

(f)

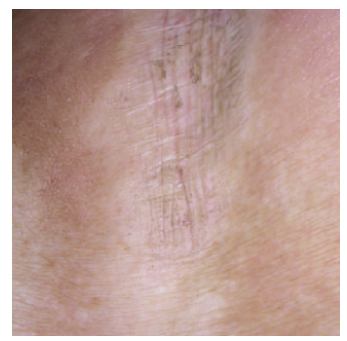

(c)

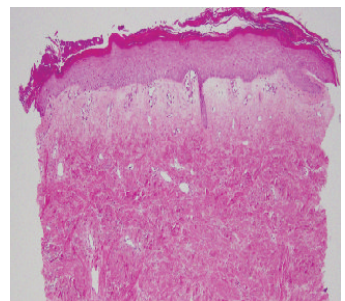

(g)

FIGURE 1: Clinical and dermatopathological findings in a patient carrying a novel LEMD3/Man1 (Trp620X) mutation. (a-c) Morphea lesions. (a) Skin lesions involving abdomen. Note indurated periumbilical skin. (b) Close-up highlighting ruptured periumbilical bulla. (c) Indurated skin on chest. (d-g) Histopathology from lesional skin. (d, f) Abdominal skin, H\&E, 20x (d) and 50x (f). (e, g) Chest skin, H\&E stain 20x (e) and 50x (g).

frequently on the trunk. The etiology of morphea is unknown and its pathogenesis remains poorly understood.

Transforming growth factor-beta (TGF- $\beta$ ) is a multifunctional cytokine implicated in fibrosis in multiple organs [13]. The profibrotic responses elicited by TGF- $\beta$ involve both Smad-dependent canonical, as well as Smad-independent noncanonical intracellular signaling pathways $[14,15]$. Alterations in TGF- $\beta$ expression or function and in its downstream signaling mediators are implicated in the pathogenesis of localized scleroderma and systemic sclerosis [16]. Man1, the protein encoded by $L E M D 3$, is intricately linked to TGF- $\beta$ biology and has complex effects on modulating TGF- $\beta$ responses. On one hand, Manl interacts directly with TGF- $\beta$ superfamily ligands, including bone morphogenic proteins (BMPs) and activin [17]. On the other hand, Manl binds, via its C-terminal domain, directly to Smad $[17,18]$. Importantly, Man1 negatively regulates Smad-mediated TGF- $\beta$ signaling in a variety of cell types [2,17-23]. Despite these recent molecular insights, the full spectrum of LEMD3 mutations and their impact on TGF- $\beta$ biology and their functional role in the phenotypic expression of BOS remain poorly understood.

Genetic variants of LEMD3 have been associated with distinct clinical phenotypes in addition to BOS. These include isolated osteopoikilosis and melorheostosis [1, 2, 8, 24-30]. We propose that this case represents a novel variant of BOS.

\section{Case Report}

A previously healthy 72-year-old Caucasian woman presented with six months' progressive skin tightening and discoloration affecting her arms, shoulders, chest, and lower legs. Subsequently, painful erythematous patches appeared on her back, breasts, and belt line. She had no family history of scleroderma or other autoimmune disease. Physical examination demonstrated firmly indurated and hyperpigmented lesions on the arms, shoulders, chest, belt line, and lower legs and scaly erythematous and partially bullous patches over both breasts (Figures 1(a)-1(c)). She had no sclerodactyly, nailfold microvascular abnormalities or other manifestations of systemic sclerosis, and serologic tests for antinuclear, anti-Scl-70, and anti-centromere antibodies were negative. Radiographs of the hands, feet, and knees revealed numerous well-demarcated bone densities (osteopoikilosis) bilaterally (Figure 3). Based on the presence of osteopoikilosis and skin lesions, the diagnosis of BOS was made, and genomic DNA sequencing was undertaken (see below). Further investigation identified three family members (school-aged nieces and nephews on the paternal side) who had asymptomatic osteopoikilosis, but no skin lesions. Treatment of the index case included psoralens and ultraviolet light A, oral calcitriol hydroxychloroquine, and mycophenolate mofetil, as well as topical calcipotriene, betamethasone dipropropionate, and 


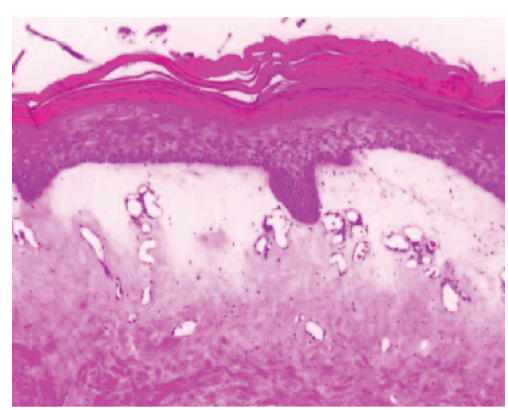

(a1)

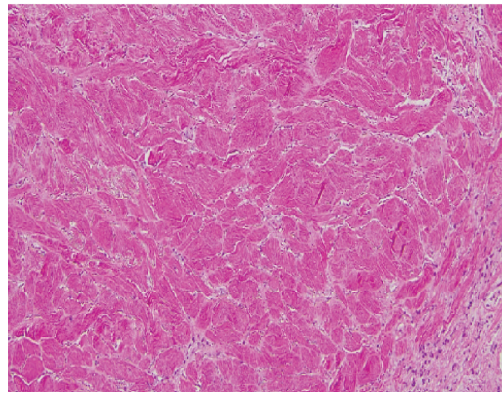

(a2)

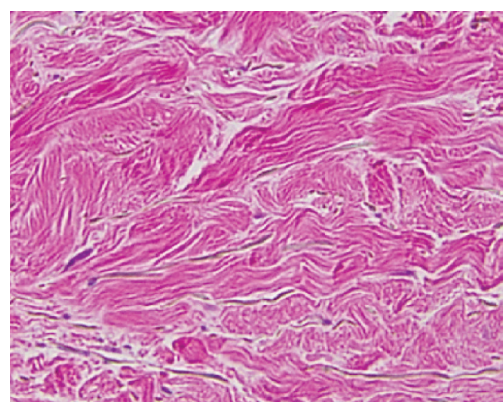

(a3)

(a)

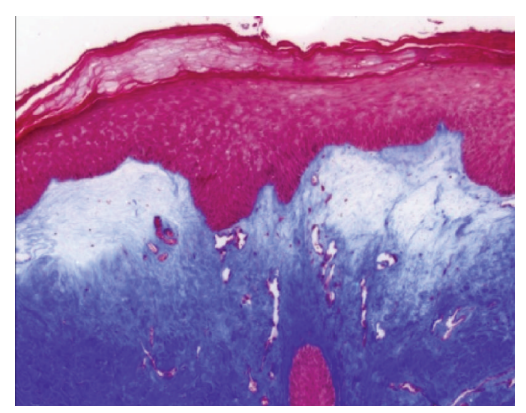

(b1)

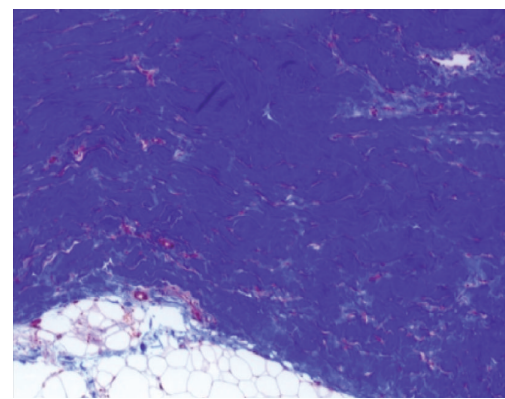

(b2)

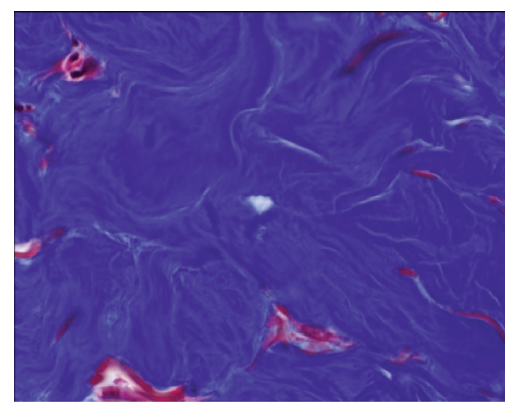

(b3)

(b)

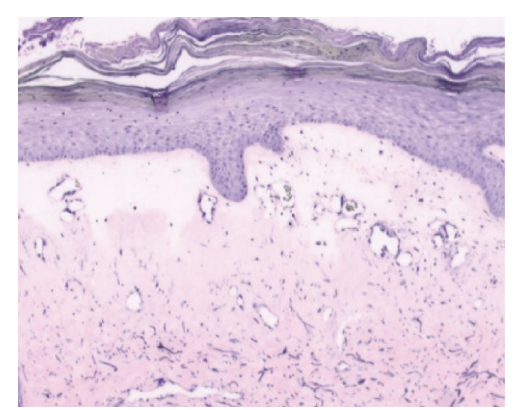

(c1)

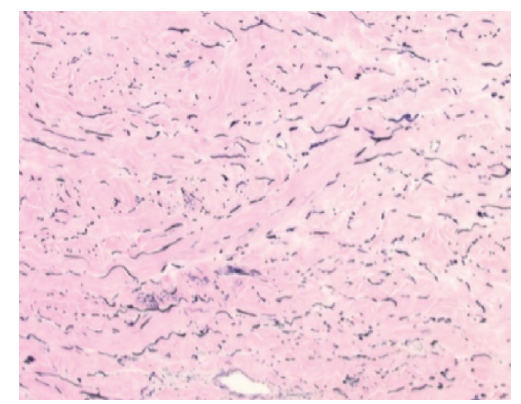

(c2)

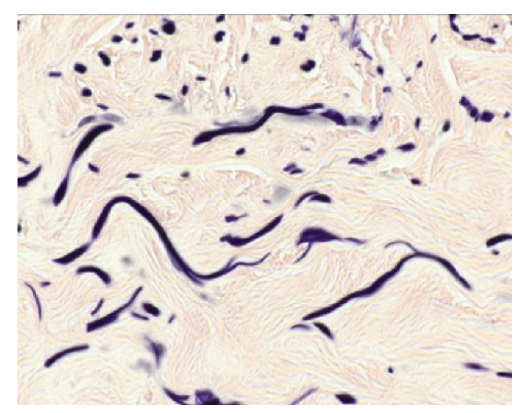

(c3)

(c)

FIGURE 2: Histochemistry of lesional skin from patient with LEMD3 Trp620X mutation. (a) H\&E stain. (b) Masson's trichrome staining. (c) Elastin staining. (a1), (b1), and (c1) represent 100x magnification of the epidermis, (a2), (b2), and (c2) represent 100x magnification of the dermis, and (a3), (b3), and (c3) show 630x magnification of the dermis. Note increase in both collagen and elastin deposition and irregular collagen fibrils.

pimecrolimus. She showed slow partial resolution of skin lesions. Subsequent course was complicated by recurrent episodes of hemorrhagic olecranon bursitis and hemorrhagic bullae over the chest, abdomen, and back.

2.1. Cutaneous Histopathology. A punch biopsy of lesional skin yielded square-shaped tissue with fibrosis and a cellular infiltrate (Figures $1(\mathrm{~d})-1(\mathrm{~g})$ ). The upper dermis showed bullous changes including edema and dilated vessels consistent with lichen sclerosus et atrophicus. Masson's trichrome and elastin stains revealed dense dermal collagen deposition and increased elastic fiber accumulation (Figure 2).

2.2. DNA Sequencing. Index case DNA was extracted from peripheral blood using a commercial kit (Sigma, St. Louis,
$\mathrm{MO})$. Sanger sequencing of the entire LEMD3 gene identified a heterozygous nonsense mutation c.1863G > A which results in a change at amino acid 621 that converts a tryptophan residue to a stop codon (p.Trp621X). This nucleotide change is predicted to truncate Manl at amino acid 621, resulting in deletion of the second transmembrane helical domain and DNA-binding and Smadinteracting domains [31] (Figure 4). The mutant gene product is predicted to lack the Smad-binding domain of Man1 required for antagonizing TGF- $\beta$ signaling. This LEMD3 mutation was not present in the exome variant server database (http://evs.gs.washington.edu/EVS/) representing 13,000 control alleles [including 8,600 alleles from individuals of European descent] or in the 1000 Genomes Project database (http://www.1000genomes.org/). 


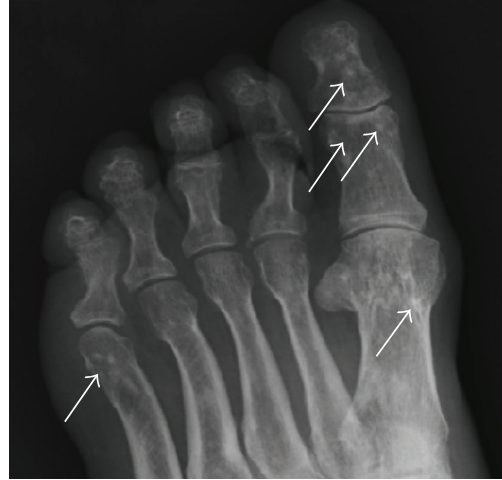

(a)

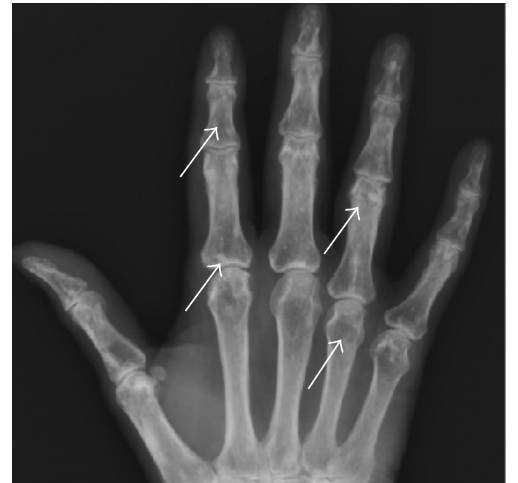

(b)

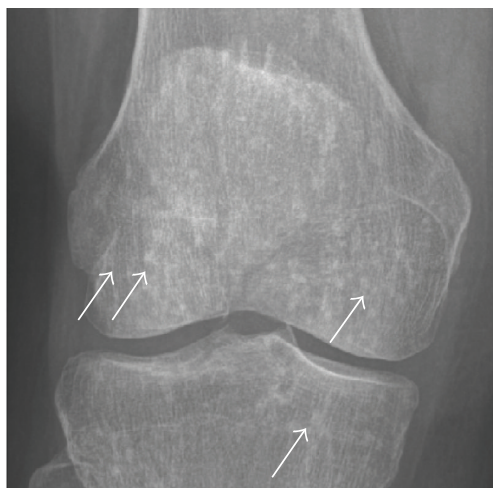

(c)

Figure 3: Osteopoikilosis. Plain radiographs. (a) Foot. (b) Hand. (c) Knee. Note multiple small (1-5 mm) sclerotic periarticular lesions consistent with bony islands of osteopoikolosis (marked by arrows).

\section{Literature Survey and Discussion}

First described in 1928, BOS is an uncommon familial syndrome characterized by osteopoikilosis associated with skin manifestations [32, 33]. In children with BOS, osteopoikilosis has been reported to be accompanied by fibrotic skin lesions, including linear scleroderma, part of the morphea spectrum disorders $[5,6,34-36]$. We are unaware of a previous description of late-onset generalized morphea associated with osteopoikilosis.

The present case might represent the coexistence of two distinct disorders affecting the skin and bone. We consider this unlikely however. As osteopoikilosis has an estimated prevalence of 2/100,000 and morphea of 0.02-0.04/100,000 [37], the extreme rarity of these two conditions makes their occurrence in the same individual by chance highly unlikely. A favored alternative explanation is that late-onset generalized morphea associated with osteopoikilosis seen in the present case is in fact syndromic and represents a novel BOS variant that falls within the phenotypic continuum linked with LEMD3 mutations.

Previous studies have led to identification of LEMD3 as the gene that is mutated in BOS [2]. In addition, different LEMD3 mutations have also been linked with nonsyndromic familial forms of both osteopoikilosis and melorheostosis [2]. In order to review current knowledge of BOS and its cutaneous manifestations, a PubMed survey using the search terms "BOS", "Ollendorf Buschke", "Buschke-Ollendorf", "osteopoikilosis", "melorheostosis", "LEMD3", and "Manl" was undertaken (Table 1). Over 30 reported cases with LEMD3 loss-of-function mutations linked with these phenotypes were identified $[1,2,8,24-28,30,38,39]$ (Table 1). Cutaneous manifestations include connective tissue nevi, fibrous nodular lesions (collagenomas or elastomas), and linear scleroderma [26].

A review of over 100 published cases of BOS showed that connective tissue nevi (dermatofibrosis lenticularis disseminata) were the most frequent cutaneous manifestation. The diagnosis of BOS was characteristically made before the age of 16. A survey of cases of LEMD3-associated skin and bony lesions revealed 28 cases of melorheostosis associated with linear scleroderma, typically affecting skin adjacent to the bone lesions, with a majority of these individuals developing linear (localized) scleroderma in childhood (Table 2). However, melorheostosis frequently occurs in the absence of LEMD3 mutations [8], and thus far none of the LEMD3 mutation-proven cases of melorheostosis (Table 1) have coincided with linear scleroderma. One report of osteopoikilosis associated with scleroderma described a patient with sclerodactyly and Raynaud phenomenon, suggesting coexistent systemic sclerosis and isolated osteopoikilosis rather than syndromic BOS [6].

LEMD3 mutations show variable penetrance. There is extreme variability in the associated phenotypes, even among individuals harboring identical mutations [2]. Given such a high degree of heterogeneity and incomplete penetrance, the causal role of any particular LEMD3 mutation in a specific phenotype is difficult to discern. Although the TGF- $\beta /$ Smad signaling pathway plays a pivotal role in both skin and bone homeostasis, it remains unclear how Man1-Smad interactions are affected by the BOS mutations, and whether they contribute to clinical features. While the novel LEMD3 mutation described in this report is predicted to alter the C-terminal domain of Manl required for R-Smad interactions [23], our functional studies failed to demonstrate consistent alterations in TGF- $\beta /$ Smad signaling in the BOS skin fibroblasts.

The coexistence of morphea and lichen sclerosus et atrophicus (LSA) changes is also of note. While this combination has been previously reported as a cause of bullous changes [40-43] in morphea, the association is relatively common in adults. A recent retrospective study confirmed the coexistence of these two entities in 26 of 91 (28.5\%) of adult morphea patients compared to only 1 of 381 children with morphea [44]. Bullous LSA changes are primarily inflammatory [45] and some have suggested that LSA may represent subepithelial morphea in this context [46]. Therefore, whether the LSA changes are related to the LEMD3 


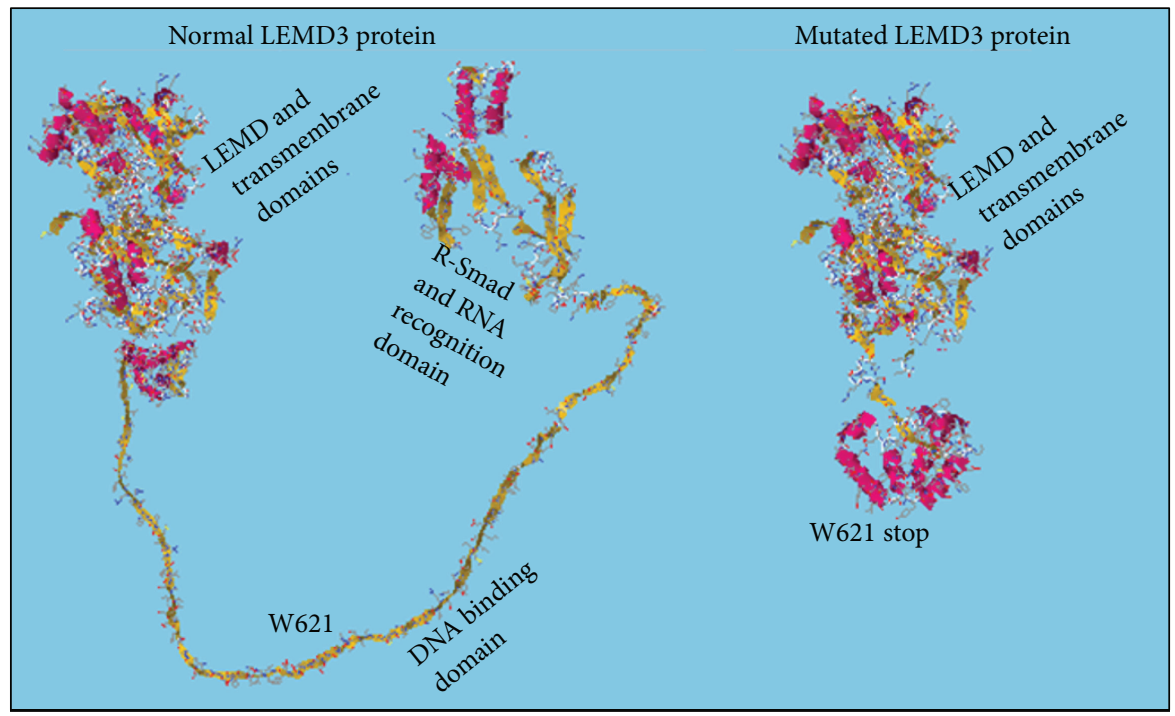

(a)

MAAAAASAPQ QLSDEELFSQ LRRYGLSPGP VTESTRPVYL KKLKKLREEE QQQHRSGGRG NKTRNSNNNN TAAATVAAAG PAAAAAAGMG VRPVSGDLSY LRTPGGLCRI SASGPESLLG GPGGASAAPA AGSKVLLGFS SDESDVEASP RDQAGGGGRK DRASLQYRGL KAPPAPLAAS EVTNSNSAER RKPHSWWGAR RPAGPELQTP PGKDGAVEDE EGEGEDGEER DPETEEPLWA SRTVNGSRLV PYSCRENYSD SEEEDDDDVA SSRQVLKDDS LSRHRPRRTH SKPLPPLTAK SAGGRLETSV QGGGGLAMND RAAAAGSLDR SRNLEEAAAA EQGGGCDQVD SSPVPRYRVN AKKLTPLLPP PLTDMDSTLD SSTGSLLKTN NHIGGGAFSV DSPRIYSNSL PPSAAVAASS SLRINHANHT GSNHTYLKNT YNKPKLSEPE EELLQQFKRE EVSPTGSFSA HYLSMFLLTA ACLFFLILGL TYLGMRGTGV SEDGELSIEN PFGETFGKIQ ESEKTLMMNT LYKLHDRLAQ LAGDHECGSS SQRTLSVQEA AAYLKDLGPE YEGIFNTSLQ WILENGKDVG IRCVGFGPEE ELTNITDVQF LQSTRPLMSF WCRFRRAFVT VTHRLLLLCL GVVMVCVVLR YMKYRWTKEE EETRQMYDMV VKIIDVLRSH NEACQENKDL QPYMPIPHVR DSLIQPHDRK KMKKVWDRAV DFLAANESRV RTETRRIGGA DFLVWRWIQP SASCDKILVI PSKVWQGQAF HLDRRNSPPN SLTPCLKIRN MFDPVMEIGD QWHLAIQEAI LEKCSDNDGI VHIAVDKNSR EGCVYVKCLS PEYAGKAFKA LHGSWFDGKL VTVKYLRLDR YHHRFPQALT SNTPLKPSNK HMNSMSHLRL RTGLTNSQGS S

(b)

\begin{tabular}{lcc}
\multicolumn{3}{c}{ LEMD3 domains } \\
\hline & Normal protein & Mutant protein \\
\hline LEM domain & Present & Present \\
Transmembrane helical domain 1 & Present & Present \\
Transmembrane helical domain 2 & Present & Absent \\
DNA binding domain & Present & Absent \\
R-Smad interacting domain & Present & Absent \\
RNA recognition motif & & \\
\hline
\end{tabular}

(c)

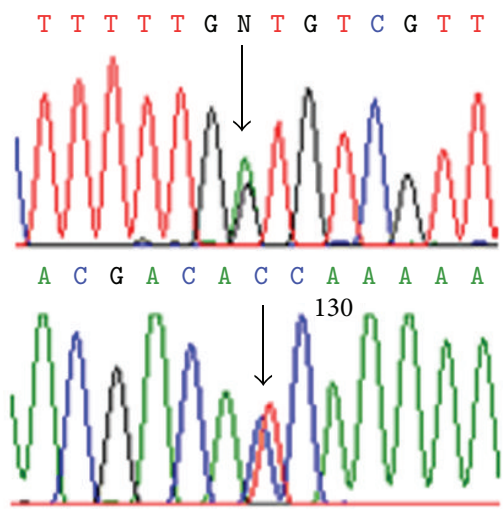

(d)

FIGURE 4: Characterization of novel LEMD3 mutation. (a) 3D predicted conformation of native and mutated p.Trp620X Man1 protein (EsyPred3d modeling software) [31]. Note deletion of the DNA-binding and R-Smad recognition domains. (b) Amino acid sequence of Man1; letters represent amino acids as defined by IUPAC. The Trp620X codon is indicated. (c) List of functional domains and presence of domains in normal and mutated Man1 protein. (d) DNA sequence of LEMD3, highlighting the novel c.1863G > A mutation. 
TABLE 1: Previously reported LEMD3 mutations.

\begin{tabular}{|c|c|c|}
\hline Point mutations & $94 \mathrm{X}$ & Buschke-Ollendorff syndrome [30] \\
\hline \multirow{11}{*}{ (Missense/nonsense) } & $457 \mathrm{C}>\mathrm{T}$ & Osteopoikilosis [2] \\
\hline & $620 \mathrm{X}$ & Buschke-Ollendorff syndrome (present study) \\
\hline & $641 \mathrm{X}$ & Buschke-Ollendorff syndrome [4] \\
\hline & $1323 \mathrm{C}>\mathrm{A}$ & Osteopoikilosis [28] \\
\hline & $1609 \mathrm{C}>\mathrm{T}$ & Osteopoikilosis and Melorheostosis [2] \\
\hline & $1801 \mathrm{G}>\mathrm{T}$ & Osteopoikilosis [8] \\
\hline & $1873 \mathrm{C}>\mathrm{T}$ & Melorheostosis [39] \\
\hline & $1913 \mathrm{~T}>\mathrm{A}$ & Melorheostosis [8] \\
\hline & $2032 \mathrm{C}>\mathrm{T}$ & Osteopoikilosis [25] \\
\hline & $2203 \mathrm{C}>\mathrm{T}$ & Buschke-Ollendorff syndrome [1] \\
\hline & $2564 \mathrm{G}>\mathrm{A}$ & Buschke-Ollendorff syndrome [29] \\
\hline \multirow{8}{*}{ Insertions/deletions/duplications/indels } & 332_333 ins TC & Buschke-Ollendorff syndrome [28] \\
\hline & 830 dupA & Melorheostosis [8] \\
\hline & 1033-1035 delGGGinsC & Osteopoikilosis [2] \\
\hline & 1185 dup T & Osteopoikilosis [2] \\
\hline & 1914 dupA & Buschke-Ollendorff syndrome [8] \\
\hline & $1941+5$ delG & Osteopoikilosis [2] \\
\hline & 2154 dupA & Osteopoikilosis [2] \\
\hline & Entire gene deletion & Osteopoikilosis [2] \\
\hline None & & Buschke-Ollendorff syndrome [47] \\
\hline \multirow{2}{*}{ Splicing } & IVS1 ds +1 G-A & Collagenoma [26] \\
\hline & IVS12 ds +1 G-A & Buschke-Ollendorff syndrome [48] \\
\hline
\end{tabular}

TABLE 2: Cases of scleroderma-spectrum disease and LEMD3-type bony lesions.

\begin{tabular}{|c|c|c|c|c|c|c|}
\hline Study (1st author) & $\begin{array}{c}\text { Juvenile-onset } \\
\text { linear } \\
\text { scleroderma }\end{array}$ & $\begin{array}{c}\text { Adult-onset } \\
\text { linear } \\
\text { scleroderma }\end{array}$ & $\begin{array}{l}\text { Systemic } \\
\text { sclerosis }\end{array}$ & $\begin{array}{c}\text { Generalized } \\
\text { morphea }\end{array}$ & Melorheostosis & Osteopoikilosis \\
\hline Thompson [49] & $\mathrm{x}$ & & & & $\mathrm{x}$ & \\
\hline Maroteaux [9] & $\mathrm{x}$ & & & & $\mathrm{x}$ & \\
\hline Muller [10] & $\mathrm{x}$ & & & & $\mathrm{x}$ & \\
\hline Pascaud-Ged [50] & $\mathrm{x}$ & & & & $\mathrm{x}$ & \\
\hline Moreno Alvarez [51] & $\mathrm{x}$ & & & & $\mathrm{x}$ & \\
\hline Saghafi [7] & $\mathrm{x}$ & & & & $\mathrm{x}$ & \\
\hline Soffa [52] & $\mathrm{x}$ & & & & $\mathrm{x}$ & \\
\hline Takeda [53] & $\mathrm{x}$ & & & & $\mathrm{x}$ & \\
\hline Nakajima [54] & $\mathrm{x}$ & & & & $\mathrm{x}$ & \\
\hline Miyachi [55] & $\mathrm{x}$ & & & & $\mathrm{x}$ & \\
\hline Siegel [56] & & $\mathrm{x}$ & & & $\mathrm{x}$ & \\
\hline Birtane [57] & & $\mathrm{x}$ & & & $\mathrm{x}$ & \\
\hline Endo [58] & & $\mathrm{x}$ & & & $\mathrm{x}$ & \\
\hline Shivanand [12] & & $\mathrm{x}$ & & & $\mathrm{x}$ & \\
\hline Weissmann [6] & & & $\mathrm{x}$ & & & $\mathrm{x}$ \\
\hline Present case & & & & $\mathrm{x}$ & & $\mathrm{x}$ \\
\hline
\end{tabular}

$\mathrm{x}$ : presence of feature in case report. 
mutation or are simply part of the morphea phenotype is unclear.

\section{Summary}

In summary, we describe a case of osteopoikilosis associated with late-onset generalized morphea and associated LSA changes in an elderly individual carrying a previously undescribed familial mutation in LEMD3. We propose that in this case morphea and osteopoikilosis are linked, representing a novel BOS variant that is on the continuum of LEMD3associated skin and bone manifestations. In light of the known involvement of Man1 in modulating canonical TGF$\beta$ signaling, we hypothesize that the skin and bone abnormalities associated with LEMD3 mutations might be related to altered TGF- $\beta$ signaling. Future studies will characterize the functional consequences of LEMD3 mutations and their role in the clinical manifestations of the syndrome. Given the diverse phenotypes associated with such mutations and poorly understood mechanisms of how Man1 protein changes contribute to the phenotypic manifestations of BOS, such studies may reveal new roles for this diverse molecule in mesenchymal cell biology.

\section{Competing Interests}

The authors declare that they have no competing interests.

\section{Acknowledgments}

This study was supported by grants from the NIH: K12HD055884 (Benjamin Korman), R043309 (John Varga), RO42205 (John Varga), and R01AR059703 (Polly Ferguson).

\section{References}

[1] S. Baasanjav, A. Jamsheer, M. Kolanczyk et al., "Osteopoikilosis and multiple exostoses caused by novel mutations in LEMD3 and EXT1 genes respectively-coincidence within one family," BMC Medical Genetics, vol. 11, no. 1, article 110, 2010.

[2] J. Hellemans, O. Preobrazhenska, A. Willaert et al., "Lossof-function mutations in LEMD3 result in osteopoikilosis, Buschke-Ollendorff syndrome and melorheostosis," Nature Genetics, vol. 36, no. 11, pp. 1213-1218, 2004.

[3] T. G. Woyciechowsky, M. R. Monticielo, B. Keiserman, and O. A. Monticielo, "Osteopoikilosis: what does the rheumatologist must know about it?” Clinical Rheumatology, vol. 31, no. 4, pp. 745-748, 2012.

[4] A. Korekawa, H. Nakano, Y. Toyomaki et al., "BuschkeOllendorff syndrome associated with hypertrophic scar formation: a possible role for LEMD3 mutation," The British Journal of Dermatology, vol. 166, no. 4, pp. 900-903, 2012.

[5] M. H. Mordant, "Osteopoikilosis with disseminated dermatofibrosis," Archives Belges de Dermatologie et de Syphiligraphie, vol. 14, no. 1, pp. 83-87, 1958.

[6] G. Weissmann, "Scleroderma associated with osteopoikilosis," A.M.A. Archives of Internal Medicine, vol. 101, no. 1, pp. 108-113, 1958.
[7] M. Saghafi, M. Sahebari, and L. Goshayeshi, "Linear scleroderma in association with melorheostosis," Journal of Clinical Rheumatology, vol. 16, no. 2, pp. 99-100, 2010.

[8] J. Hellemans, P. Debeer, M. Wright et al., "Germline LEMD3 mutations are rare in sporadic patients with isolated melorheostosis," Human Mutation, vol. 27, no. 3, p. 290, 2006.

[9] P. Maroteaux and M. Lamy, "Melorheostosis, osteopecilia and circumscribed scleroderma," Annales de Pédiatrie, vol. 8, pp. 576-580, 1961.

[10] S. A. Muller and E. D. Henderson, "Melorheostosis with linear scleroderma," Archives of Dermatology, vol. 88, pp. 142-145, 1963.

[11] E. Pascaud-Ged, J. Rihouet, J. L. Pascaud, and J. Rousseau, "Melorheostosis, osteopoikilosis and linear scleroderma," La Semaine des Hopitaux : Organe Fonde Par Lassociation D'enseignement Medical des Hopitaux de Paris, vol. 58, no. 17, pp. 1056-1059, 1982.

[12] G. Shivanand and D. N. Srivastava, "Melorheostosis with scleroderma," Clinical Imaging, vol. 28, no. 3, pp. 214-215, 2004.

[13] A. Leask and D. J. Abraham, "TGF- $\beta$ signaling and the fibrotic response," The FASEB Journal, vol. 18, no. 7, pp. 816-827, 2004.

[14] A. Moustakas, S. Souchelnytskyi, and C.-H. Heldin, "Smad regulation in TGF- $\beta$ signal transduction," Journal of Cell Science, vol. 114, no. 24, pp. 4359-4369, 2001.

[15] A. Moustakas and C.-H. Heldin, "Non-Smad TGF- $\beta$ signals," Journal of Cell Science, vol. 118, no. 16, pp. 3573-3584, 2005.

[16] J. Varga and B. Pasche, "Transforming growth factor beta as a therapeutic target in systemic sclerosis," Nature Reviews Rheumatology, vol. 5, no. 4, pp. 200-206, 2009.

[17] D. Pan, L. D. Estévez-Salmerón, S. L. Stroschein et al., “The integral inner nuclear membrane protein MAN1 physically interacts with the R-smad proteins to repress signaling by the transforming growth factor- $\beta$ superfamily of cytokines," The Journal of Biological Chemistry, vol. 280, no. 16, pp. 15992-16001, 2005.

[18] F. Lin, J. M. Morrison, W. Wu, and H. J. Worman, "MAN1, an integral protein of the inner nuclear membrane, binds Smad2 and Smad3 and antagonizes transforming growth factor- $\beta$ signaling," Human Molecular Genetics, vol. 14, no. 3, pp. 437445, 2005.

[19] F. Lin, D. L. Blake, I. Callebaut et al., "MAN1, an inner nuclear membrane protein that shares the LEM domain with laminaassociated polypeptide 2 and emerin," The Journal of Biological Chemistry, vol. 275, no. 7, pp. 4840-4847, 2000.

[20] W. Wu, F. Lin, and H. J. Worman, "Intracellular trafficking of MAN1, an integral protein of the nuclear envelope inner membrane," Journal of Cell Science, vol. 115, no. 7, pp. 1361-1372, 2002.

[21] A. Ishimura, J. K. Ng, M. Taira, S. G. Young, and S.-I. Osada, "Man1, an inner nuclear membrane protein, regulates vascular remodeling by modulating transforming growth factor $\beta$ signaling," Development, vol. 133, no. 19, pp. 3919-3928, 2006.

[22] L. Bengtsson, "What MAN1 does to the Smads: TGF $\beta / B M P$ signaling and the nuclear envelope," The FEBS Journal, vol. 274, no. 6, pp. 1374-1382, 2007.

[23] E. Kondé, B. Bourgeois, C. Tellier-Lebegue et al., "Structural analysis of the Smad2-MAN1 interaction that regulates transforming growth factor- $\beta$ signaling at the inner nuclear membrane," Biochemistry, vol. 49, no. 37, pp. 8020-8032, 2010.

[24] O. Dereure, "Buschke-Ollendorff syndrome: inactivating mutation of the LEMD3 gene," Annales de Dermatologie et de Vénéréologie, vol. 132, no. 6-7, part 1, p. 593, 2005. 
[25] A. R. Couto, J. Bruges-Armas, C. A. Peach et al., "A novel LEMD3 mutation common to patients with osteopoikilosis with and without melorheostosis," Calcified Tissue International, vol. 81, no. 2, pp. 81-84, 2007.

[26] D. Hershkovitz, D. B. Amitai, and E. Sprecher, "Familial cutaneous collagenomas resulting from a novel mutation in LEMD3," The British Journal of Dermatology, vol. 156, no. 2, pp. 375-377, 2007.

[27] B. Menten, K. Buysse, F. Zahir et al., "Osteopoikilosis, short stature and mental retardation as key features of a new microdeletion syndrome on 12q14," Journal of Medical Genetics, vol. 44, no. 4, pp. 264-268, 2007.

[28] S. Mumm, D. Wenkert, X. Zhang, W. H. McAlister, R. J. Mier, and M. P. Whyte, "Deactivating germline mutations in LEMD3 cause osteopoikilosis and Buschke-Ollendorff syndrome, but not sporadic melorheostosis," Journal of Bone and Mineral Research, vol. 22, no. 2, pp. 243-250, 2007.

[29] Y. Zhang, M. Castori, G. Ferranti, M. Paradisi, and B. P. Wordsworth, "Novel and recurrent germline LEMD3 mutations causing Buschke-Ollendorff syndrome and osteopoikilosis but not isolated melorheostosis," Clinical Genetics, vol. 75, no. 6, pp. 556-561, 2009.

[30] B. Burger, D. Hershkovitz, M. Indelman et al., "BuschkeOllendorff syndrome in a three-generation family: influence of a novel LEMD3 mutation to tropoelastin expression," European Journal of Dermatology, vol. 20, no. 6, pp. 693-697, 2010.

[31] C. Lambert, N. Léonard, X. De Bolle, and E. Depiereux, "ESyPred3D: prediction of proteins 3D structures," Bioinformatics, vol. 18, no. 9, pp. 1250-1256, 2002.

[32] A. Buschke, "Uber scleroderma," Wiener Klinische Wochenschrift, vol. 39, pp. 955-957, 1902.

[33] A. Buschke and H. Ollendorf-Curth, "Ein Fall von Dermatofibrosis lenticularis disseminata und Osteopathia condensans disseminata," Dermatologische Wochenschrift, vol. 86, pp. 257262, 1928.

[34] D. Loreck, I. Tausch, and H. Albrecht-Nebe, "BuschkeOllendorff syndrome: combination of dermatofibrosis lenticularis disseminata with osteopoikilosis," Radiologia Diagnostica, vol. 25, no. 3, pp. 283-291, 1984.

[35] F. Massolo, M. G. Bertazzoni, A. Caroli, S. Sardelli, M. Cellini, and E. Mazzone, "Melorheostosis linear scleroderma with osteopoikilosis. Description of a clinical case," La Pediatria Medica e Chirurgica, vol. 11, no. 5, pp. 555-557, 1989.

[36] I. Tausch, D. Loreck, H. Albrecht-Nebe, H. Klug, and T. Thormann, "Dermatofibrosis lenticularis disseminata with osteopoikilosis (Buschke-Ollendorff syndrome)," Dermatologische Monatsschrift, vol. 170, no. 5, pp. 322-331, 1984.

[37] L. S. Peterson, A. M. Nelson, W. P. D. Su, T. Mason, W. M. O'Fallon, and S. E. Gabriel, "The epidemiology of morphea (localized scleroderma) in Olmsted County 1960-1993," The Journal of Rheumatology, vol. 24, no. 1, pp. 73-80, 1997.

[38] E. Ben-Asher, E. Zelzer, and D. Lancet, "LEMD3: the gene responsible for bone density disorders (Osteopoikilosis)," Israel Medical Association Journal, vol. 7, no. 4, pp. 273-274, 2005.

[39] J. K. Gass, J. Hellemans, G. Mortier, M. Griffiths, and N. P. Burrows, "Buschke-Ollendorff syndrome: a manifestation of a heterozygous nonsense mutation in the LEMD3 gene," Journal of the American Academy of Dermatology, vol. 58, supplement 1, no. 5, pp. S103-S104, 2008.

[40] J. A. K. Patterson and A. B. Ackerman, "Lichen sclerosus et atrophicus is not related to morphea. A clinical and histologic study of 24 patients in whom both conditions were reputed to be present simultaneously," American Journal of Dermatopathology, vol. 6, no. 4, pp. 323-335, 1984.

[41] S. Shono, M. Imura, M. Ota, A. Osaku, S. Shinomiya, and $\mathrm{K}$. Toda, "Lichen sclerosus et atrophicus, morphea, and coexistence of both diseases: histological studies using lectins," Archives of Dermatology, vol. 127, no. 9, pp. 1352-1356, 1991.

[42] S. Yasar, C. T. Mumcuoglu, Z. A. Serdar, and P. Gunes, "A case of lichen sclerosus et atrophicus accompanying bullous morphea," Annals of Dermatology, vol. 23, supplement 3, pp. S354-S359, 2011.

[43] M. Taveira, M. Selores, V. Costa, and A. Massa, "Generalized morphea and lichen sclerosus et atrophicus successfully treated with sulphasalazine," Journal of the European Academy of Dermatology and Venereology, vol. 12, no. 3, pp. 283-284, 1999.

[44] A. Kreuter, J. Wischnewski, S. Terras, P. Altmeyer, M. Stücker, and T. Gambichler, "Coexistence of lichen sclerosus and morphea: a retrospective analysis of 472 patients with localized scleroderma from a German tertiary referral center," Journal of the American Academy of Dermatology, vol. 67, no. 6, pp. 1157$1162,2012$.

[45] A. Rencic, S. Goyal, M. Mofid, F. Wigley, and H. C. Nousari, "Bullous lesions in scleroderma," International Journal of Dermatology, vol. 41, no. 6, pp. 335-339, 2002.

[46] S. Virdi and A. J. Kanwar, "Generalized morphea, lichen sclerosis et atrophicus associated with oral submucosal fibrosis in an adult male," Indian Journal of Dermatology, Venereology and Leprology, vol. 75, no. 1, pp. 56-59, 2009.

[47] M. Yadegari, M. P. Whyte, S. Mumm et al., "Buschke-Ollendorff syndrome: absence of LEMD3 mutation in an affected family," Archives of Dermatology, vol. 146, no. 1, pp. 63-68, 2010.

[48] H. Kobayashi, M. Kasahara, M. Hino et al., "A novel heterozygous splice-site mutation of LEM domain-containing 3 in a Japanese kindred with Buschke-Ollendorff syndrome," Journal of Endocrinological Investigation, vol. 30, no. 3, pp. 263-265, 2007.

[49] N. M. Thompson, C. E. Allen, G. S. Andrews, and F. N. Gillwald, "Scleroderma and melorheostosis; report of a case," The Journal of Bone and Joint Surgery, vol. 33, no. 3, pp. 430-433, 1951.

[50] E. Pascaud-Ged, J. Rihouet, J. L. Pascaud, and J. Rousseau, "Melorheostosis, osteopoikilosis and linear scleroderma," Annales de Radiologie Medecine Nucleaire, vol. 24, no. 8, pp. 643-646, 1981.

[51] M. J. Moreno Alvarez, M. A. Lázaro, G. Espada, H. A. Barceló, and A. Maldonado Cocco, "Linear scleroderma and melorheostosis: case presentation and literature review," Clinical Rheumatology, vol. 15, no. 4, pp. 389-393, 1996.

[52] D. J. Soffa, D. J. Sire, and J. H. Dodson, "Melorheostosis with linear sclerodermatous skin changes," Radiology, vol. 114, no. 3, pp. 577-578, 1975.

[53] T. Takeda, N. Ogura, S. Jodo et al., "A case of melorheostosis with linear sclerodermatous skin changes," Ryumachi, vol. 35, no. 3, pp. 580-584, 1995.

[54] I. Nakajima, R. Okuyama, H. Tagami, S. Aiba, and Y. Kuramoto, "Linear melorheostotic scleroderma without melorheostosis," Acta Dermato-Venereologica, vol. 86, no. 2, pp. 163-164, 2006.

[55] Y. Miyachi, T. Horio, A. Yamada, and T. Ueo, "Linear melorheostotic scleroderma with hypertrichosis," Archives of Dermatology, vol. 115, no. 10, pp. 1233-1234, 1979.

[56] A. Siegel and H. Williams, "Linear scleroderma and melorheostosis," British Journal of Radiology, vol. 65, no. 771, pp. 266-268, 1992. 
[57] M. Birtane, M. Eryavuz, H. Ünalan, and F. Tüzün, "Melorheostosis: report of a new case with linear scleroderma," Clinical Rheumatology, vol. 17, no. 6, pp. 543-545, 1998.

[58] H. Endo, A. Katsumi, K. Kuroda, A. Utani, H. Moriya, and H. Shinkai, "Increased procollagen $\alpha 1$ (I) mRNA expression by dermal fibroblasts in melorheostosis," British Journal of Dermatology, vol. 148, no. 4, pp. 799-803, 2003. 


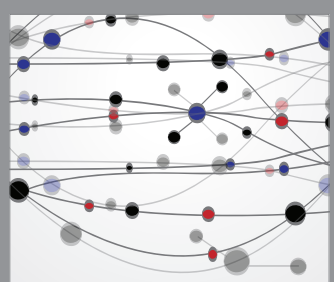

The Scientific World Journal
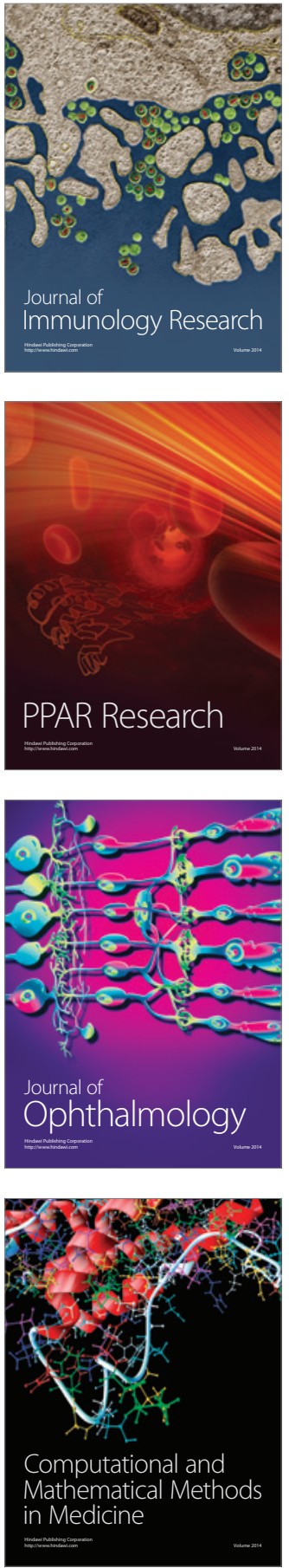

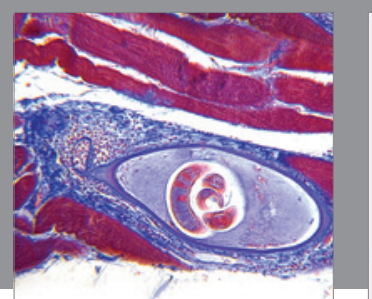

Gastroenterology Research and Practice

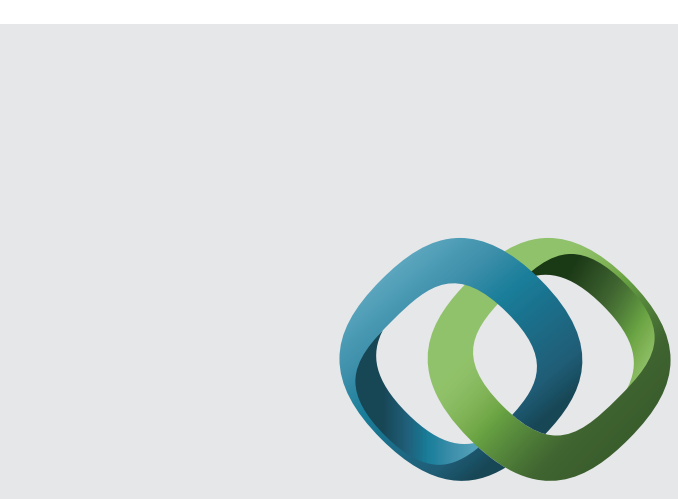

\section{Hindawi}

Submit your manuscripts at

http://www.hindawi.com
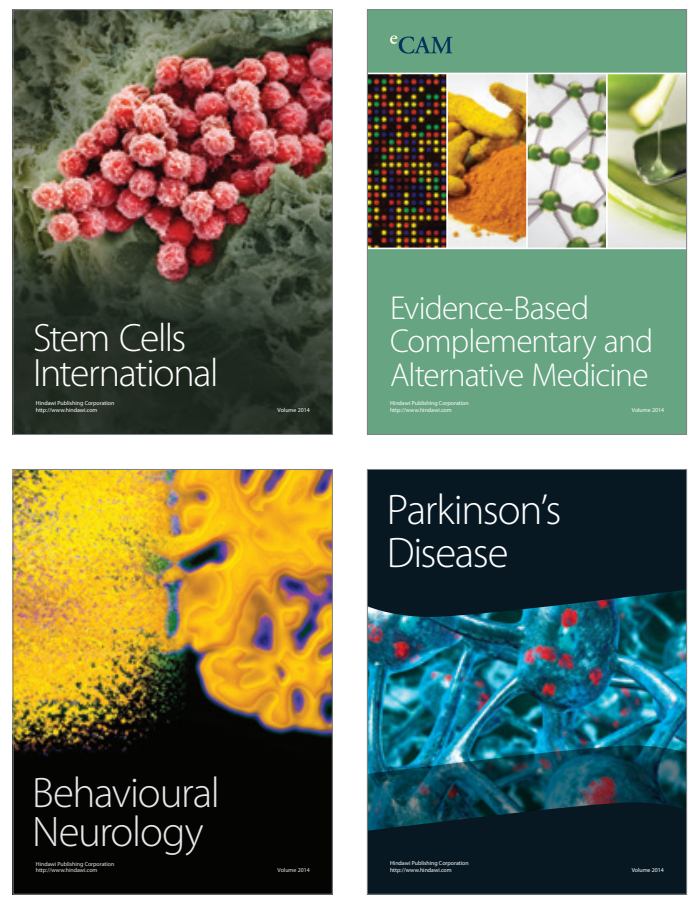
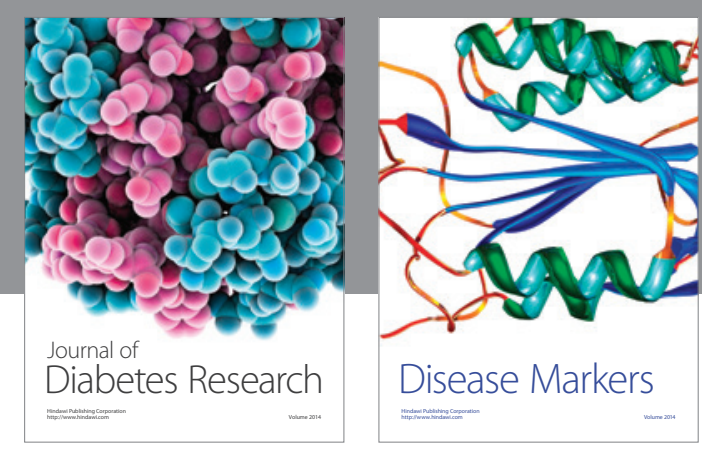

Disease Markers
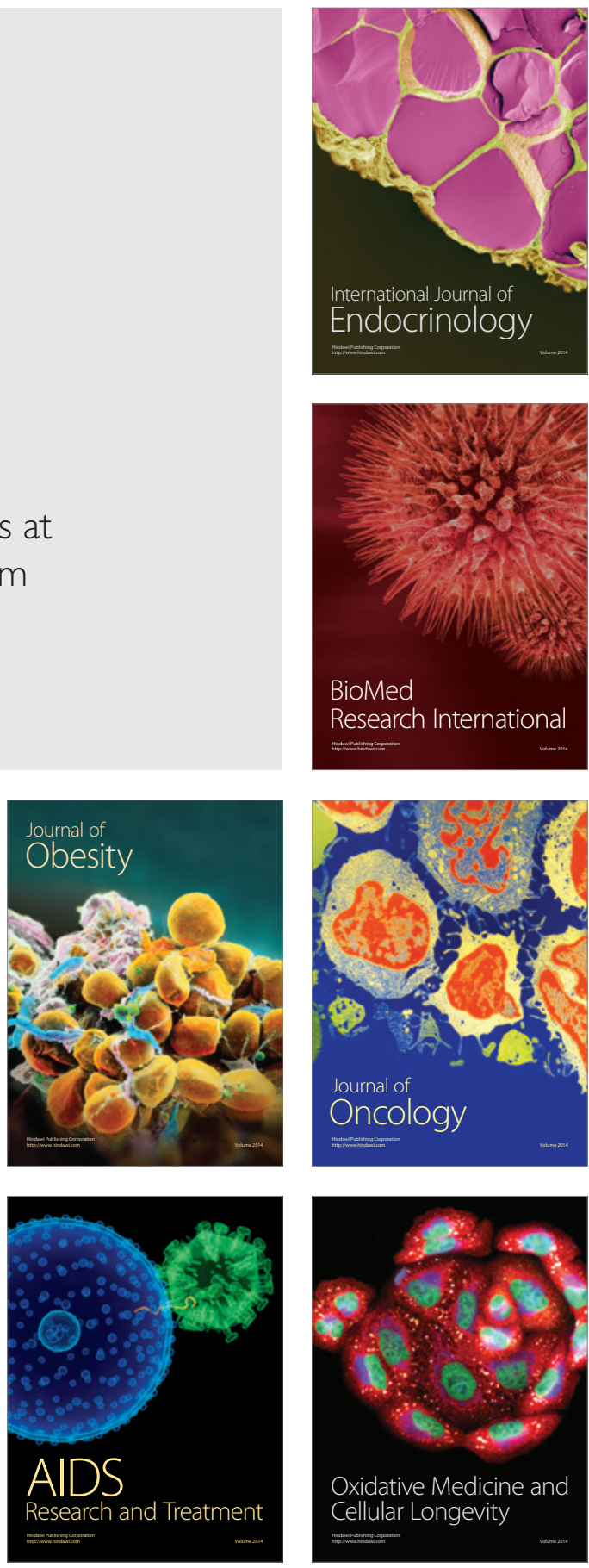